\title{
Kant, Hegel, and the Bounds of Thought
}

\section{Katerina Deligiorgi}

Hegel's relation to Kant is often portrayed in terms of epistemic impatience. For W.H. Walsh, for example, whereas Kant seeks to 'demonstrate that certain kinds of thing [cannot] be objects of human knowledge', and thus that there are 'limits to men's cognitive aspirations', ${ }^{1}$ Hegel issues the 'demand that thought be free to range unchecked wherever it chooses' and claims the 'Absolute' as an object of human knowledge. ${ }^{2}$ There are two flaws in this standard account. First, it underestimates the cognitive confidence of Kant's project of a critique of pure reason. Central to this project is the idea that reason has the resources to adjudicate its own claims and thus to know itself. Second, it neglects Hegel's conception of dialectic as the inner discipline of thought. I shall deal with each of these issues in turn. The first part of the paper examines the intellectual commitments entailed by the very idea of a critique of pure reason; the second part addresses the boundary-determining function of dialectic. A fuller understanding of what is meant by 'critique' and 'dialectic' should enable us not only to re-assess Hegel's relation to Kant, but also to retrieve their shared conception of philosophical reflection as rational selfknowledge. The aim of this paper therefore is to highlight the common ground between the two projects, rather than to emphasise their critical distance. I seek to show that Hegel shares Kant's conviction that 'philosophy consists in knowing its bounds' (seine Grenzen zu kennen), ${ }^{3}$ even though he accords such knowledge a different status from Kant.

How are we to understand Kant's notion of a critique of reason? One well-known interpretation, offered by Strawson, takes its cue from the tradition of 'classical empiricism'. 4 On this view, Kant's contribution is to show that our experience is more structured than the empiricists are willing to allow. The critique of reason is consequently understood as criticism of reason's fraudulent claims to possess metaphysical knowledge. 'The first task of philosophy is to set its own limits', Strawson cautions. This appears to have an unmistakably Kantian ring. But, does it? On Strawson's account, setting limits consists in identifying the boundary between knowledge and nonsense. This is done through the 'principle of significance', which stipulates that 'there can be no legitimate, or even meaningful, employment of ideas or concepts which does not relate them to empirical or experiential conditions of their application' ${ }^{6}$ This is an attractive reading that makes good sense of a key proposition defended in the Critique, namely that 'thoughts without intuitions are empty', or that a concept that is not related to an object of possible experience 'has no sense (Sinn), and is entirely empty of content'. 


\section{BULLETIN OF THE HEGEL SOCIETY OF GREAT BRITAIN}

However, Strawson's interpretation is unsatisfactory in at least one respect. By interpreting Kant's notion of an 'empty' thought as a meaningless thought, it places Kant in the invidious position of having to explain how meaning arises by the mere addition of sensible content. This would suggest that Kant is indeed an empiricist, seeking to derive the meaning of concepts from sensory input. But this is clearly not Kant's position. Rather he insists that intuition and the understanding each make a distinctive and irreducible contribution to our knowledge of objects: 'thoughts without concepts are empty' and 'intuitions without concepts are blind ${ }^{9}{ }^{8}$ In other words, we cannot claim that we know something unless that of which we speak conforms with the formal conditions of possible experience. Conversely, the unschematised categories are not meaningless, but merely lacking objective or, as Kant puts it, 'determinate meaning'. ${ }^{9}$ This fits with his insistence that the categories are the basic functions or forms of thought of an object in general: 'we cannot think an object save through categories' ${ }^{10}$ He further clarifies that 'for thought the categories are not limited by the conditions of our sensible intuition, but have an unlimited field'. ${ }^{\text {II }}$ It is precisely because the categories open up this unlimited field that we employ them in judgements that have no empirical content. We are thus tempted to apply the concept of existence to God, or that of substance to the soul. Whilst a desire to avoid getting entangled in such dialectical thickets may well motivate Strawson's reading, I believe that there are grounds other than hermeneutic fidelity on which it should be resisted. The clean separation that Strawson proposes between Kant's 'analytical argument' and the dark transcendentalism of the 'synthetic $a$ priori' sets the stage for the fundamentally Humean conclusion, which Strawson elsewhere endorses, namely that there is no such thing as the reasons for which we hold our basic epistemic beliefs. ${ }^{12}$ Capitulation to this Humean position, however, leaves us with a problematic and unsatisfactory conception of the limits of rational reflection, which are treated as something essentially inexplicable, an unfathomable given that at the same time is responsible for the good running of the epistemic practices it determines. This is precisely, however, the position Kant sets out to refute in the Critique of Pure Reason. On Kant's view, the task of philosophy is not to set its own limits, but rather to know them.

As outlined in the Introduction and the two Prefaces to the Critique of Pure Reason, this task appears initially to raise contradictory demands. In the Introduction, Kant compares human reason to a light dove which, cutting through the air and feeling its resistance, imagines how much freer it would be in airless space. He then uses this metaphor to illuminate the problem with Plato's attempt to transcend the 'narrow limits' (enge Schranken) of the world of sense and to employ his reason in the 'empty space of pure understanding', an environment that offers 'no resistance' but also 'no support' for thought. ${ }^{13}$ The meaning of these remarks seems clear: transcendent or speculative reasoning is frictionless and thus fruitless. It is surprising, then, that only a few pages earlier Kant claims that reason demands 'by necessity and with every right' to go beyond the bounds (Grenzen) of experience. ${ }^{14}$ What are we to make of this? We can understand Kant's invocation of 'necessity' here as a reference to reason's natural propensity to 
occupy itself with questions it cannot answer. ${ }^{15}$ It is less clear how we should interpret his invocation of reason's 'right' to transcend the bounds of experience. If Kant is affirming this right, then he seems to be condoning what he elsewhere criticises. If, on the other hand, the critique is going to show that this right is usurpatory, then this is an unpromising start for reason's criticism of itself, for how are we to trust the deliverances, critical or otherwise, of such a naturally wayward faculty? There is, however, a third option that explains both the need for a critique of reason and the conditions that make such critique possible. What Kant claims is that, its metaphysical proclivities notwithstanding, reason actually has the resources to sustain normative reflection upon its own claims. To use one of Kant's favourite metaphors, we could say that reason has the right to adjudicate in its own tribunal. Contra Hume, then, Kant believes that reason is active in the sense that it is capable of critical self-reflection. Reason, he maintains, is not like a 'pupil' who indiscriminately copies his teacher's words, but like a judge 'who compels the witness to answer questions which he himself has formulated'. ${ }^{16}$ This has important implications for our understanding Kant's conception of 'limits'. Unlike Spinoza, Locke, Leibniz, or Hume, all of whom subscribed to a form of the claim that human reason is limited, Kant argues that human reason is self-limiting. The key claim here is that the limits of rational reflection are not something we discover, as if they were a brute fact of our human constitution, but rather something for which we account discursively. They are not the external hindrances that Plato sought to transcend, but rather rationally defensible 'bounds'.

But what model of philosophical reasoning can provide knowledge of the bounds of rational reflection? Kant gives a revealing answer to this when he compares philosophical and mathematical reasoning. He contends that the latter is an inadequate model for the former. Mathematics, he argues, can 'present (darstellen) the complete, original concept of a thing within the bounds of its concept'. ${ }^{17}$ 'Bounds' here means 'precision' in enumerating the characteristics or 'marks' (Merkmale) that give the complete concept. ${ }^{18}$ To have a definition of a concept, it is therefore necessary to know its 'bounds'. Kant insists, however, that the completeness required for such a boundary-setting exercise is only achievable in mathematics. The reason lies in a basic difference between the two disciplines, to which Kant frequently alludes, namely that, unlike philosophy, mathematics 'constructs' its concepts: the boundaries of a mathematical concept can be drawn precisely because the concepts into which it is analysed also make up, or 'construct' their object. ${ }^{19}$ With philosophy it is otherwise, for philosophy deals either with empirical or with a priori concepts. The boundaries of empirical concepts are labile; they change as our knowledge of the object changes. Precision is, therefore, unobtainable. ${ }^{20}$ The boundaries of a priori concepts, among which Kant includes the familiar metaphysical concepts of cause and substance, but also concepts such as right and equity, present a different problem. Kant claims that a priori concepts admit of 'exposition' (Expositio) only, which 'the critic can accept as being up to a point valid, though still entertaining doubts as to the completeness of the analysis'. ${ }^{21}$ Apart from a desire to placate the critic, what are Kant's reasons for arguing that $a$ 
priori concepts cannot be defined? Doesn't reason after all have insight into what it produces after a plan of its own? Kant argues as follows:

I can never be certain that the clear representation of a still confused concept has been completely developed, unless I know that it is adequate to the object. But since the concept of it, as it is given, can contain many obscure representations, which we overlook in our analysis although we always use them in our application of the concept, the completeness of the analysis of my concept is always in doubt. ${ }^{22}$

The argument here is relatively straightforward: clarity in my representation of a concept is not a sufficient criterion for the adequacy of my definition of it. What is required is that the representation of a concept be adequate to its object. But we can only think the object through the concept we seek to define, and in thus using the concept we may well employ representations that do not appear in our 'definition'. Kant's claim about the impossibility of a complete definition thus allows him indirectly to make the point that what we really want to find out, namely how concepts enable us to think objects, cannot be given definitionally. Although Kant employs the Leibnizian-Wolffian vocabulary of conceptual analysis (clear/obscure, distinct/confused), he argues in effect that concepts are not simply 'ideas', which we can hold in our mind's eye, inspect, and exhaustively define, but rather rules for mental acts. Their bounds, therefore, are not constructible $a$ priori, like those of mathematical concepts, but neither are they revisable a posteriori, like those of empirical concepts. Rather they are determinable $a$ priori by means of what he calls here 'exposition' and elsewhere 'analysis' (Zergliederung). Whilst these claims draw on theses defended in earlier stages of the critique, their significance here lies in the way Kant uses them to articulate the 'how' of philosophical reasoning, or what he calls the 'method of knowledge through pure reason' ${ }^{23}$ By abjuring the type of certainty and clarity identified with mathematical reasoning, Kant bids farewell, once and for all, to the Cartesian foundationalist project. The self-knowledge of reason, which as we know from the Preface is 'the most difficult of all its tasks' ${ }^{24}$ should not be understood therefore as a mutated Cartesian project that is guided by the ideal of a transparent grounding of metaphysical claims. Neither, however, should Kant's position be seen as a retrenchment. It is rather a redeployment of philosophical reasoning, for Kant reclaims for reason the task of normative self-reflection that the empiricists had relinquished. This emerges clearly in Kant's criticism of Locke whom he accuses of opening wide the doors to 'enthusiasm' (Schwärmerei). ${ }^{25}$ This accusation seems odd given that Locke explicitly advises philosophical caution, and is, if anything, a cognitive pessimist. Kant, however, argues that Locke's 'recommendations of moderation' are ineffectual because reason will not be kept within 'limits' (Schranken) 'once it has authority on its side'. Kant's argument is that because Locke identifies de facto limitations of human understanding, he fails to address the normative question of what can count as knowledge, and thus ultimately 


\section{BULLETIN OF THE HEGEL SOCIETY OF GREAT BRITAIN}

fails to answer the question 'what can I know?'. It is this omission that opens the doors to enthusiasm.

To show that reason is capable of critical self-reflection, and thus that the task of selfknowledge of reason announced in the Prefaces is indeed possible, a defense is required of the model of philosophical reasoning just described. This would provide an account of the bounds of rational reflection by treating the question of the use and abuse of rational concepts. This account, I shall argue, is given in the Antinomy of Pure Reason. On Kant's definition, 'antinomy' is the condition of inner conflict in which reason finds itself when it seeks to know the 'unconditioned'. Kant gives four instances of such conflict that relate to 'cosmological' questions, such as, for instance, whether the world has a beginning in time or whether it is composed of simple substances. As is well-known, it is puzzling over this condition of inner conflict in reason that aroused Kant from his 'dogmatic slumber and drove him to the critique of reason itself.$^{26}$ Unfortunately, few commentators share Kant's estimation of the importance of the Antinomy. Bennett thinks it so ill-conceived that he finds himself constrained to acknowledge that 'I cannot take seriously the title of Kant's great masterpiece. Considered as a critique of pure reason, the Critique of Pure Reason is negligible'. ${ }^{27}$ Strawson, who also considers the argument a failure, is nonetheless sympathetic to what he sees as the 'demolition' function of the Antinomy, which shows that key pieces of metaphysical reasoning are what Kant calls houses of cards (Kartengebäude). One of the few fully to recognise the importance of the antinomy is Allison, who interprets it as a type of transcendental argument that reveals the incoherence of a cosmological idea that 'both purports to refer and explicitly exempts itself from the conditions under which reference is possible'. ${ }^{28}$ The advantage of Allison's reconstruction is that it makes perspicuous Kant's argument against 'transcendental realism', which 'dogmatically' presupposes that objective reality is a given. However, the claim that we cannot know something without being in possession of the conditions of its knowability hardly seems worth the trouble of the elaborate construction of four antinomies. I shall argue that although the antinomy is indeed supposed to provide indirect support for the central epistemic thesis of the Critique, it fulfils another important task that Allison overlooks: antinomial reasoning is the means by which reason gains self-knowledge.

In the Preface to the B edition, Kant gives us an important clue for how we should read the Antinomy. He argues that the deduction is merely the 'first assessment of our rational cognition a priori' and that only with the antinomy are we able to carry out a 'cross-check' (Gegenprobe) of the results of the deduction. ${ }^{29}$ Kant compares his procedure in constructing the antinomies to that of the natural scientist who sets up an experiment and assures his readers that the 'attempt to think' the objects of pure reason 'will provide a splendid touchstone' of the new method of thinking, that we can know a priori of things only 'what we ourselves have put into them ${ }^{30}$ The problem with these assurances, of course, is that because what is to be tested in this case is a method of cognition a priori, we cannot appeal to experience as can 'those who study nature ${ }^{31}$ What is then the touchstone that will furnish the Gegenprobe of Kant's theory? Kant 


\section{BULLETIN OF THE HEGEL SOCIETY OF GREAT BRITAIN}

describes it as follows: 'if we now find that there is agreement with the principle of pure reason when things are considered from this twofold standpoint [i.e. as appearances and as things in themselves], but that an unavoidable conflict of reason with itself arises with a single standpoint, then the experiment decides for the correctness of that distinction, ${ }^{32}$ It would seem, then, that the 'splendid touchstone' invoked earlier is none other than the principle of contradiction, which reason itself supplies and with which our 'attempt to think' the objects of pure reason must necessarily comply. It is by testing the possibility of agreement and conflict of reason with itself that the mere 'attempt to think' something functions as a Gegenprobe.

The question now is whether contradiction can yield any positive results. That Kant intends the Antinomy to yield positive results is stated clearly in the promise that transcendental philosophy can satisfy all our enquiries: 'among all speculative cognition, transcendental philosophy has the special property that there is no question at all dealing with an object given by pure reason that is insoluble by this very same human reason'. ${ }^{33}$ The antinomies are presented therefore as an advance over earlier attempts at speculative cognition. Whereas traditional metaphysics has failed to solve the cosmological puzzles treated in the antinomies, Kant will show that they are soluble. His strategy is to show that it is not faulty reasoning that causes the problem, but a faulty assumption that underpins such reasoning. What is this faulty assumption? In Allison's interpretation, what is assumed is simply the truth of 'transcendental realism', or that appearances are things in themselves. Whilst this is a position that we are indeed asked to discount at the end of the Antinomy, ${ }^{34}$ it cannot be the assumption that motivates the antinomial conflict. As Walsh points out, this is because it is either trivially wrong (an appearance is not a thing in itself), or wrong only if we are already convinced of the truth of transcendental idealism. ${ }^{35}$ In either case, the Antinomy cannot be thought of as providing a genuine touchstone for the new method of thinking. There is, however, another assumption shared by both the thesis and the antithesis perspectives. We can identify this common assumption, if we follow the interpretative line originally proposed by Sadik Al-Azm, who interprets the antinomies with reference to the Leibniz/Newton dispute set out in Leibniz's correspondence with Clarke. ${ }^{36}$ In the correspondence, the dispute is presented as a disagreement about the application of the principle of sufficient reason to which both parties subscribe. ${ }^{37}$ Both Leibniz and Clarke agree that without the principle 'that nothing happens without a reason why it should be so and not otherwise' no metaphysical propositions could ever be demonstrated. ${ }^{38}$ Yet what for one counts as a sufficient reason is for the other a reason to prolong the search for it. The problem is generated by the principle of sufficient reason itself. It is a substantive principle masquerading as a formal one: it does not stipulate that for every event there is a cause, but rather that there is a 'reason' that exhaustively determines the result and is immediately recognisable as such. Kant harnesses the inherent ambiguity of this principle to show that whilst both parties assume that there is a state of affairs that fully justifies their respective positions, thus bringing the enquiry to a close, they fail to agree about what it is that has this explanatory power. The resulting conflict is thus genuinely immanent, for it arises from a hitherto 


\section{BULLETIN OF THE HEGEL SOCIETY OF GREAT BRITAIN}

uncontested principle of metaphysical reasoning. Kant's criticism of the search for the unconditioned should be seen then as a criticism of this principle, which he renders as follows: 'if the conditioned is given, then the whole sum of conditions, and hence the absolutely unconditioned, is also given through which alone the conditioned was possible'. ${ }^{39}$ This criticism in turn plays a key role in the logon didonai of reason because the principle of sufficient reason sustains a particular conception of reason as a faculty that enables us to gain access to ultimate facts about the universe. By showing how this trusted principle produces a conflict within reason, Kant is able to challenge this conception of reason.

The Antinomy thus fulfils a twofold task: it cross-checks the new method of cognition $a$ priori by showing that any knowledge we purport to have without reference to these a priori conditions is fool's gold. Most importantly though, it contributes to the task of reason's selfknowledge by challenging the conception of reason as a disclosive faculty. Therefore, the legitimacy or illegitimacy of our cognitive claims is not to be decided by attempts to get to the 'real per se'. But how should we go about the task of thinking the objects of pure reason? As revealed in the antinomies, reason's internal cross-checking mechanism is the familiar principle of contradiction. We learn something about reason through antinomial reasoning, which is what provides here 'resistance' and thus also 'support' for our thinking. This positive role of contradiction as a boundary-determining operation, indeed, as a tribunal of pure reason, supports the earlier claims that the bounds of rational reflection are not obstacles surveyed from afar, but rather possessions, which we do not hold upon sufferance but which are rightfully ours.

\section{II}

The purpose of the tribunal of pure reason is to place metaphysics on the secure path of science. Yet reading the Preface to the first edition of Hegel's Science of Logic, we find a very gloomy assessment of the fortunes of the queen of the sciences. In what seems to be a deliberate echo of the Preface to the first edition of the Critique of Pure Reason, Hegel laments that metaphysics has been 'extirpated root and branch and has vanished from the ranks of sciences'. ${ }^{40}$ The main culprit, he claims, is none other than the 'exoteric teaching of the Kantian philosophy', which instructs that the understanding ought not to go beyond experience lest it generate 'fantasies of the brain'. ${ }^{41}$ Although we are not told what Kant's esoteric teaching might be, we are, I believe, given an important clue by Hegel's description of the requirement that philosophy must fulfil if it is to be 'science'. Philosophy, he argues, cannot borrow its method from mathematics, any more than it can rely on the 'categorical assurances of inner intuition' ${ }^{42}$ Rather, its 'method of knowing' must be generated out of its own 'content'. Although it is as yet unclear how such an autochthonously philosophical method will be generated, it is not difficult to detect in this declaration an echo of the thesis that 'reason has insight into what it produces after a plan of its own'. ${ }^{43}$ As I argued previously, this thesis should be understood as proposing that the claims of reason must be adjudicated internally, rather than by reference to some external realm of facts. 
through self-criticism. Yet in the opening pages of Hegel's 'system of pure reason ${ }^{, 44}$ we do not find anything that resembles Kant's direction that reason undertake normative reflection on its claims. Instead, Hegel describes his project as an 'exposition' (Darstellung) of the 'selfmovement' of 'pure thoughts'. ${ }^{45}$ When he does discuss the normative question - most explicitly in the opening section of the Logic entitled 'With what must science begin?' - he insists that the content of the Logic is immanently organised in a 'spiritual movement' that 'gives itself its own determinateness and in its determinateness its equality with itself ${ }^{46}$ This may lead us to suspect that, rather than letting thought range 'unchecked wherever it chooses', as Walsh fears, Hegel seeks to confine it within a rigorous but quasi-hermetic system that sets its own conditions of intelligibility.

The most powerful version of this criticism has been put forward by Michael Rosen. Rosen's interpretation is of especial interest because he combines the familiar view of the KantHegel relation I sketched at the beginning of the paper with the one that I would like to defend, namely that dialectic functions as the inner discipline of thought. Rosen attributes to Hegel the belief that 'philosophy need not be restricted, as Kant had thought it must, to the finite, merely discursive sphere'. ${ }^{47}$ On Rosen's account, Hegel's supposed abandonment of the 'discursive sphere' is a symptom of his 'speculative Neo-Platonism' ${ }^{48}$ And the problem with speculative Neo-Platonism is that whilst it is wrong, it cannot be shown to be wrong, because its 'truth' depends on the dialectical 'experience of Thought', which Rosen calls 'hyperintuition'. ${ }^{49}$ What blocks the critical evaluation of Hegel's claims and ensures the 'first-hand' or 'experiential' character of dialectical proof is 'immanent criticism'. Unlike ordinary criticism, immanent criticism absorbs all opposition into itself by working every criticism, or 'negation', into a positive result that propels the dialectic forward. Rosen objects that this view of dialectic is peculiar to Hegel and sustained by his 'speculative-mystical' conception of thinking. 'Negation', he argues, need not be like chiselling a block of marble, which always leaves a new shape, but more like unravelling a knot in a piece of string. ${ }^{50}$ On Rosen's account, therefore, dialectic is indeed the inner discipline of thought, but the condition of engagement with dialectically formed thought is resignation to it and abandonment of our critical faculties. Whilst I think that Rosen is right in criticising the hermeticism and incipient irrationalism of this type of project, I think he wrongly attributes such a project to Hegel. Taking my cue from Hegel's use of contradiction, which Rosen entirely ignores, I shall argue that the dialectic is a type of antinomial reasoning that is used to determine as fully as possible the bounds of thought.

Hegel says little about bounds (Grenzen). What he does say is mainly in the first part of the Logic, the Doctrine of Being. His treatment of the topic there, however, shows that the question of bounds remains 'live' for the entire 'system of pure reason'. The concept of 'bound' appears in the context of a discussion of 'determinateness' (Bestimmtheit), that is, of how something can be said, objectively and necessarily, to be so and so. Hegel's treatment of determinateness in the Doctrine of Being is very similar to Kant's treatment of definition in the Discipline of Pure Reason. What he is after is the 'complete, original concept of a thing within 


\section{BULLETIN OF THE HEGEL SOCIETY OF GREAT BRITAIN}

the bounds of its concept' or, in Hegel's terminology, the 'concrete whole' in the 'form of being' that is 'posited' as such in its 'own self. ${ }^{51}$ The concept of 'bound' is introduced as a promising candidate for 'determinateness'. This is because the 'bound' of something just is its 'immanent determination', 52 and thus enables us to think something fully as it is, without reference to any external conditions. However, in what appears to be a sudden change of register, Hegel further identifies 'bound' with something 'finite'. ${ }^{53} \mathrm{He}$ then explains that finite things 'are, but the truth of their being is their end', so that 'the hour of their birth is the hour of their death'. 54

How do we get from determining something to finite somethings? The section starts with a problem: we determine something by reference to some 'other', which, however, cannot be determined unless our original 'something' functions as its 'other'. ${ }^{55}$ This vacillation from one to the other is frustrating because our aim is to capture the 'isolated' thing as it is, rather than as it is relative to a set of contingently thrown together 'others'. ${ }^{56}$ One way out of this, Hegel suggests, is by distinguishing between the 'abstract', 'inner quality', or 'determination' of a thing and its 'external' or 'relational' features. The concept of a 'bound' captures the 'determination' of something, or what something is, whilst internalising the other-relation that frustrated the previous attempt at 'determinateness'. The bound is thus the 'non-being of the other'. ${ }^{57}$ The thought here is that in order to determine something, that is, in order to distinguish between the bundles of qualities that make up 'something' and 'other', we must already somehow be able to distinguish between basic and relational features of each thing. So, for example, to say that the boundary of the desk is its 'not being' floor is simply an awkward way of saying that in order to know where one thing stops, or 'ceases to be', and an other thing begins, I must already have a sense of the basic 'determination' of 'desk' and 'floor'. It is here that Hegel's discussion takes what looks like a sharp metaphysical turn. 'Determination' is explained teleologically as an 'ought to be' that something 'fulfils'. ${ }^{58}$ To grasp the 'immanent determination' or 'bound' of something appears, then, to incur a teleological cost. Now we can see why the entire section bears the heading 'Finitude', for if we think of the telos of something as its being, it is not difficult to interpret 'bound' in terms of finite things, whose being is precisely their end. But how useful or even appropriate is it to think about determinateness in this way? We may grant that knowing what something is capable of becoming can help explain why it is the way it is. This type of 'boundary-setting', however, is only possible, if we already know what the end of something is, that is, if we already know what is to count as its relevant features (or, thinking dialectically, what the relevant 'other' is). But this is precisely what we seek to discover. Since we cannot assume such knowledge as given, the concept of bound must remain empty.

Although the teleological path leads us to a problematic conclusion -we need to presuppose what we seek to discover- Hegel's teleological elaboration of the concept of 'bound' makes, nonetheless, an important contribution to the earlier discussion of determinateness. This is initially obscured because Hegel employs a typically allusive 
vocabulary. 'Determination', he argues, is 'the unrest of the something in its bound (Grenze), in which it [the something] is immanent, an unrest which is the contradiction which impels the something out beyond itself ${ }^{59}$ Determination appears here to be an organic rather than a logical process. Hegel's examples re-inforce this impression. He claims, for instance, that the point dialectically transcends its limitation to become a line; that 'in oxidation', the base 'transcends its limit (Schranke) of existing only as a base', ${ }^{, 60}$ that the plant 'transcends the limitation of being a seed'; and that 'in the limitation of hunger' the sentient creature 'is the urge to overcome this limitation' ${ }^{61}$ In these examples Hegel uses 'limit' (Schranke) to refer to a particular state of something, the state of being a point, a base, a seed, hungry, etc. Although these examples can be read teleologically, the emphasis is not on the purported telos of the something, but on the instability of its 'limit': thus, points become lines, bases oxidise, etc. What is the significance of this for determinateness? It means, quite simply, that in order to identify something as a seed, one needs to know all sorts of things about seeds, including that they grow into plants, but that not all one knows to be true of seeds is relevant in determining 'seed'. This is a clarification or 'exposition' (Darstellung) of the original question of determinateness. By the end of the section on bounds, we discover that what we seek is a way of re-identifying something in different contexts, or of recognising it through its different states, or again, of taking the 'limits' of the thing as belonging in its 'immanent determination' or 'bound'. This, however, is not a summative process, whereby every possible state or 'limit' of the thing is added up, but rather a selective process, because not everything that is the case about something counts as its immanent determination. It is in summing up these results that Hegel makes the famous claim that to fix a limit (Schranke) is already to transcend it. ${ }^{62}$

But what sort of outcome is this? We are certainly not given a set of instructions for achieving determinateness. Do we then have a positive result, a 'new shape' as Rosen suggests? It does not quite seem so. What we find out is that adequately to bound something, or to obtain a genuinely immanent determination, we must be satisfied that the elements or 'limits' (Schranken) we select are not arbitrarily chosen features, or as Hegel says later, the result of merely 'external reflection of the subjective thinker'. ${ }^{63}$ Should this then be understood as a negative result, an admission that we simply don't know in what immanent determination consists? This does not seem right either, for what Hegel is thematising here is the question of criteria. He claims that determining is a kind of choosing that involves reflection on what counts as immanent, essential, relevant, etc. It turns out, therefore, that to determine something we need also to have an account of how such determining works. To put it differently: the other-relation that is internalised in the notion of a 'bound' gradually comes to mean not a relation between things or between states of a thing, but between what is being thought and thinking itself. Since what is at issue is precisely determinateness, however, we have no independent insight into the second-order question of what is required for determination in this demanding sense. This is Hegel's version of the Kantian claim that we cannot compare the object with its concept because we think the object through its concept. We could say, therefore, that Hegel's argument 
advances by determining further our original question of 'determinateness'. It addresses the question as to how something can be said, objectively and necessarily, to be so and so. The clarification or exposition of this question, in turn, takes the form of criticism of those approaches that are found wanting and are, therefore, ruled out. Contrary to Rosen's suggestion, then, we can see that dialectic resembles neither untying a knot in a piece of string nor chiselling marble. It is better described as a critique of thought. This, of course, is not a term that Hegel uses; unless, that is, he is criticising the Kantian version. But Hegel does have a precise equivalent, which he uses to designate the self-criticism of thought. This term, which is a key element of the dialectic, is 'contradiction'.

Hegel's discussion of contradiction has not generally been well-received. ${ }^{64} \mathrm{His}$ apparent endorsement of contradiction is indeed puzzling. To make matters worse, he says contradictory things about contradiction. In the section on bounds that we have just discussed, 'contradiction' is presented as a problem for thought; Hegel shows that in seeking to determine something both as it changes and as it is essentially, thought is 'caught up' and 'held' in contradiction. ${ }^{65}$ Yet he also asserts that 'intelligent reflection [...] consists in grasping and asserting contradiction' ${ }^{66}$ How are we to make sense of this? We need to begin by forming a clearer idea about what Hegel means by 'contradiction'. This is not as obvious as some critics have insisted. ${ }^{67}$ Like Kant, Hegel is not interested in mere pairs of opposites, but in what we may call 'conditioned' pairs of opposites. Kant explains this by contrasting the statement 'all bodies are either goodsmelling or not good-smelling' with the pair 'all bodies have a good smell'/ 'all bodies have a smell that is not good ${ }^{68}$ The difference consists in this: the latter has a hidden premise, 'all bodies have a smell', which may or may not be true, since it could be that some bodies have no smell at all (in Kant's terminology the latter is a pair of 'dialectical contradictories'). The idea of the hidden premise, which Kant employs here, is also central to Hegel's argument in the Logic. Although Kant attributes this type of argumentation to Zeno, whom he praises for being a 'subtle dialectician', ${ }^{69}$ its more immediate source is a scholastic argument about essential predication. Hegel's reliance on this argument is most in evidence in the section on Judgement. Hegel uses the example: 'this action is good'. ${ }^{70}$ The predicate 'good' gives us the essential property of the action; it cannot change without the action's changing. By contrast, a predicate designating a contingent property can change without affecting the subject. What enables us to identify the subject and 'posit' (ponere) its determination is a hidden premise, which, in this example, can be something like: 'helping a friend in need'. ${ }^{71}$ In the type of judgement treated in this scholastic argument, therefore, we have another promising candidate for determinateness. On Hegel's definition, indeed, 'judgement' just is 'the determinateness of the Notion posited in the Notion itself. ${ }^{72}$ 'Judgement' is thus a form of 'bound' that enables us to grasp the 'underlying notion', or 'the essence' of the thing. ${ }^{73}$ Significantly, however, Hegel focuses neither on the subject nor on the predicate terms of judgement, but rather, on what Kant calls the Verhältniswort, the "small word "is", which 'serves to posit the predicate in its relation to the 
subject' ${ }^{74}$ Having pared down the unit ' $s$ is $P$ ' to the unifying function of 'is', Hegel then claims that, in order to fulfil this function, 'is' must also 'posit' an 'is not' relation:

What the judgement enunciates to start with is that the subject is the predicate; but since the predicate is supposed not to be what the subject is, we are faced with a contradiction which must resolve itself, pass over into a result. ${ }^{75}$

The contradiction arises because, for the judgement to be both genuinely informative and essentially determining, the copula must have both a predicative function (' $s$ is $P$ ' is informative, if $P$ is different from $s$ ) and an identity function (' $s$ is $P$ ' is determining, if $P$ is $s$ and nothing else). ${ }^{76}$ At first blush, this seems like an artificial problem. When I say 'this action is good' I don't also say 'this action is not good'. True, 'good' is also predicable of other subjects, besides this one. Using ' $s$ is not $P$ ', 'this action is not good', to express the thought that universals determine by being predicable to more than one particular seems forced. This 'contradiction' arises only because we have an ambitious conception of determination: we want to form a judgement that is both genuinely informative and essentially determining. We could say, then, that the 'hidden premise' that produces the contradiction is the conception of determination we started with. But this is not the whole story. For what we are confronted with here is a variation on the problem of bounds: that which enables us to grasp the thing as it is is a relation to an 'other'. In the context of the discussion of bounds, the question at issue is: what is the relevant 'other'? Here, the question is: what is the nature of this other-relation? In judgement, the 'other' of the subject under determination is the predicate and thus the relation that gives us the concept of the thing just is the thing; the 'determinateness of the Notion' is 'posited in the Notion itself $;{ }^{77}$ or, in Hegel's examples, 'this action is good', 'Gaius is learned', 'the rose is a plant'. But successful predication in these instances is premised on a further other-relation that is only implicitly acknowledged in these judgements. What enables us to identify the subject as so and so is a further 'hidden' premise about this action, Gaius, or the rose. So, although subject and predicate are held together in a single judgement, the way this judgement determines depends on a more complex procedure than that given in ' $s$ is $P$ '. Hegel's insistence that $s$ is also not $P$ simply alerts us to this. Contradiction thus serves to exhibit the complexity of judgement by complicating the seemingly straightforward role of the copula 'is'.

We can see now that contradiction is not part of a mystical or irrationalist project, but rather an integral part of the dialectical 'bounding' of thought, by means of which Hegel seeks to sharpen the questions that arise in trying to think even the simplest thing, viz. what something is. It has a 'boundary-setting' role in that it encourages us to search for reasons for the conceptual choices we make and for the intellectual commitments we undertake in using terms such as 'subject', 'predicate', 'particular', 'universal'. Hegel's project can, therefore, properly be called a 'critique of thought'. This is a critique with emphatically positive results: the unconditioned or absolute determinateness of the 'Idea'. However, the 'Idea' is not an extra 
piece of knowledge, but merely the end point of a line of argument that Hegel pursues in the Doctrine of Notion and that aims to present (darstellen) thought as a unity of thought and thinking, or of determination and conditions of determination. The key, or in Hegel's terms, the "soul and substance ${ }^{78}$ of the Logic is the dialectical discipline: the most full determination of the bounds of thought is thus not contained in the absolute Idea but dialectically thought through.

We are now in position to see that, despite the important differences between Kantian critique and Hegelian dialectic, both projects present us with a similar conception of the task of philosophy. Both identify philosophy as a search for rational self-knowledge. From our contemporary perspective, informed largely by a deflationary conception of the role of philosophical reflection, this kind of search appears foredoomed. However, as I have sought to show, despite their cognitive confidence and philosophical ambition, these projects are not predicated on an assumption of rational impeccability or transparency. Rather, the pursuit of rational self-knowledge takes the form of an exposition of the bounds of thought.

Katerina Deligiorgi APU, Cambridge

1 W. H. Walsh 'The Idea of a Critique of Pure Reason', in Stephen Priest (ed.), Hegel's Critique of Kant (Clarendon: Oxford, 1987), p.119, and p. 125.

2 Walsh, ibid., p. 125.

3 I. Kant, Critique of Pure Reason, trans. N. K. Smith. (London: Macmillan, 1964), A 727/B755. Cited according to the standard ' $A$ ' and ' $B$ ' pages of the first and second editions; henceforth $C P R$. In the following, I employ 'bounds' to translate 'Grenzen' and 'limits' to translate 'Schranken'. This is to acknowledge a slight but consistent difference of use in Kant, and in Hegel. Kant tends to use Schranke to mean restriction or external limitation, while giving Grenze a more positive sense of a boundary that is established to reason's own satisfaction. In Hegel, the use of the two terms is more localised but the difference is even more pronounced, with Grenze having again the more positive sense of determination of a thing, whereas Schranke (also translated as 'limitation') signifies a limit to be overcome.

4 On Strawson's account, the tradition of what he terms 'classical empiricism' stretches to include exponents of twentieth-century radical empiricism, as is evident in his attempt to illuminate Kant's position by employing a version of A. J. Ayer's 'criterion of significance'.

$5 \quad$ P.F.Strawson, The Bounds of Sense (Methuen: London, 1966), p.17.

6 Strawson, ibid., p. 16; emphasis added.

$7 \quad C P R$ A 239/B298; see also CPR B145, A 240/B299. Although in B 149 Kant claims that 'our sensible and empirical intuition alone can give them [i.e. the concepts] sense (Sinn) and meaning (Bedeutung)', he makes clear that the concepts are not thereby nonsensical. They are 'empty' (leer) and lacking 'objective reality' (objektive Realität). The employment of the term 'objective reality' has a polemical edge here, because realitas objectiva was employed in scholastic philosophy to mean precisely an idea in the mind and not a feature of the external world. Just in the previous paragraph, in the process of distinguishing between what can be thought and what can be known, Kant makes a 
similar point with reference to mathematical concepts, which, he claims, are not knowledge 'by themselves' (B 148), yet clearly not meaningless either. Strawson's employment of the principle of significance tends to conflate the Kantian distinction between thinkable and knowable. A better way of capturing Kant's critical intentions, I suggest, is by paying attention not only to the conditions of the proper use of concepts, but also to the conditions of abuse, which Kant explores in the Antinomy of Pure Reason.

$8 \quad C P R$ A 51/B 75; see also A 19, A 69/B 93.

9 CPR A 244.

$10 \quad C P R$ B 165.

$11 \quad C P R$ B 166n.

12 P. F. Strawson, Skepticism and Naturalism; Some Varieties (Methuen: London, 1985), p.20. Strawson's reasons for endorsing this position is that he considers it as a potent anti-sceptical weapon, one that defuses, rather than answers sceptical doubt. However, the Humean thesis is derived from a premise that we are not constrained to accept, namely that reason is limited to knowledge of relations and of matters of fact. Kant's argument about a critique of reason requires that we entertain a different conception of the role and capacities of reason.

$13 \quad C P R$ A 5/B 9.

$14 \quad C P R$ Bxx, emphasis added.

15 The Critique of Pure Reason opens, of course, with the idea that human reason by nature overreaches itself: 'Human reason has this peculiar fate that in one species of its knowledge it is burdened by questions which, as prescribed by the very nature of reason itself, it is not able to ignore, but which, as transcending all its powers, it is also not able to answer', Avii.

$16 C P R$ Bxiii.

$17 \quad C P R$ A $727 /$ B755.

$18 \quad C P R$ A 727/B755n

19 See also CPR A 713-4/B741-2; A 719/B747; A 837/B865; A 239-40/B298-9; see too, the Preamble of the Prolegomena. On mathematical construction, see M. Friedman, Kant and the Exact Sciences (Harvard, 1992), esp. pp.90ff.

20 Kant fully admits that empirical concepts are revisable, arguing that 'new observations remove some properties and add others; and thus the boundaries of the concept are never assured' $C P R$ A 728/B756.

$21 \quad C P R$ A $729 / \mathrm{B} 757$.

22 CPR A 728/B 756.

23 CPR A 712/B 740.

$24 \quad C P R$ A xi.

$25 \quad C P R$ B 128.

26 Letter to Christian Garve, A. Zweig (ed.), Kant's Philosophical Correspondence, (University of Chicago Press, 1967), p. 252.

27 Jonathan Bennett, Kant's Dialectic (Cambridge University Press, 1974), p. 3. Bennett is not alone in his negative estimation of the antinomy of pure reason: see also Strawson, and more recently Paul Guyer, The Claims of Reason (Cambridge University Press, 1987), pp. 385-415. Henry Allison is a notable exception here. I discuss his position below. 
28 Henry Allison, Kant's Transcendental Idealism; An Interpretation and Defense (Yale: New Haven, 1983), pp.35-61, here p.56.

$29 \quad C P R$ Bxx.

$30 \quad C P R$ Bxviii.

$31 \quad C P R$ Bxviiin.

$32 \quad C P R$ Bxixn.

33 CPR A 477/B505.

$34 \quad$ CPR A 537/B565.

35 W. H. Walsh, Kant's Criticism of Metaphysics (Edinburgh, 1975), pp. 197ff. I rely here on Walsh's excellent discussion on the relevance of the principle of sufficent reason to understanding the antinomies.

36 S. J. Al-Azm, The Origins of Kant's Arguments in the Antinomies (Oxford University Press, 1972).

37 See, Leibniz, Third Paper: 'The author grants me this important principle, that nothing happens without a sufficient reason why it should be so and not otherwise. But he grants it only in words and in reality denies it. That shows that he does not fully perceive the strength of it'; in G. H. R. Parkinson (ed.), G. W. Leibniz, Philosophical Writings (Everyman, 1995), p.211.

38 Leibniz, Second Paper, ibid., p.207.

39 CPR A 409/ B435.

40 G. W. F. Hegel, The Science of Logic, trans. A.V. Miller (Humanities Press, 1989), p. 25; henceforth SL. References to the German are to G. W. F. Hegel, Wissenschaft der Logik Bd.I,II (Suhrkamp, 1986).

41 'Hirngespinste', SL 25.

$42 \quad S L 27$.

$43 \quad C P R$ Bxiii.

$44 \quad S L 50$.

$45 \quad S L 28$.

46 SL ibid., emphases added; see also $S L$ 37, 45.

47 M. Rosen, Hegel's Dialectic and Its Criticism (Cambridge, 1984), p.106.

48 Rosen, ibid., p.179.

49 Rosen, ibid., p.77.

50 Rosen, ibid., p. 32-3.

$51 \quad S L 110$.

$52 \quad S L 117$.

53 SL ibid.

$54 \quad S L 129$.

$55 \quad S L 118$.

$56 S L 120$.

$57 \quad S L 126$.

$58 \quad S L 123$.

$59 \quad S L 128$.

$60 \quad S L 134$.

$61 S L 135$.

$62 \quad S L 134$.

$63 \quad S L 384$. 


\section{BULLETIN OF THE HEGEL SOCIETY OF GREAT BRITAIN}

64 Hegel's contemporaries accused him of inconsistency and worse. In his History of Modern Philosophy, Schelling argues that Hegel confuses the 'is' of predication with the 'is' of identity, a criticism later repeated by Russell; see 'Hegel', trans. A. Bowie in Hegel: Critical Arguments (Routledge: London, 1993). Schopenhauer considered it a 'colossal mystification [which] will furnish posterity with an inexhaustible source of sarcasm' (Die beiden Grundprobleme der Ethik, Bd. 4.2., p.xix). Among the exceptions, which also contain some of the best accounts of Hegel's views on contradiction, are R. Aquila, 'Predication and Hegel's Metaphysics', Kant-Studien 64 (1973), 231-45; R. Pippin, 'Hegel's Metaphysics and the problem of Contradiction', Journal of the History of Philosophy 3 (1978); and K. Dulckeit 'Hegel's Revenge on Russell: The 'is' of Identity versus the 'is' of Predication', in W. Desmond (ed.) Hegel and his Critics (Albany: SUNY Press, 1989).

$65 \quad S L$ 128; see also $S L 129,133,136$.

66 SL 441; see also SL 439, 442.

67 E. Tugendhat, Selbstbewusstsein und Selbstbestimmung. Sprachanalytische Interpretation (Suhrkamp: Frankfurt am Main, 1979), p.318.

$68 \quad C P R$ A 503/B 531.

69 CPR A 502/B530.

70 SL 626.

71 There is an asymmetry in essential predication in that the subject can change, in which case a different predicate will be appropriate: if, for instance, my help to the needy friend consists in helping him cheat someone, the 'essence' of the action can be re-considered and re-described.

$72 S L 623$.

73 SL 624.

$74 \quad C P R$ A599/B627.

75 SL 630.

76 Hegel's concern with essential predication helps also explain why he does not count as a judgement the proposition 'Aristotle died at the age of 73, in the fourth year of the 115th Olympiad' ( $S L 626$, see also $S L$ 657-8). What he is after is judgements in which ' $a$ is $F$ ' where $F$ is an essential predicate of $a$ and ' $F a$ ' is genuinely informative.

77 SL 623.

78 SL 826. 